\title{
Understanding Queer Normality: LGBT+ Representations in Millenial Flemish Television Fiction
}

\section{Florian Vanlee', Frederik Dhaenens', and Sofie Van Bauwel'}

\begin{abstract}
Queer television studies scholarship tends to construct "queerness" and "normality" as incommensurable concepts, defining queer "against the normal rather than the heterosexual." In this article, we show how this construction is specifically intertwined with highly liberalized media contexts, and generates a fundamentally static understanding and operationalization of the concept of normality in queer television studies. Turning to Flemish television fiction of the late 1990s, we point to a dynamic and open-ended approach toward sexual and gender diversity, and illustrate how televised normality itself can be a queer phenomenon. In doing so, we offer a framework to understand the proliferation of LGBT+ characters and storylines in twenty-first-century Flemish television fiction, and contribute to a nuanced understanding of the dynamics of normalization and television fiction in a western European television industry.
\end{abstract}

\section{Keywords}

LGBT+ representations, Flemish TV fiction, queer television studies, public broadcasting

\section{LGBT+ Televisibility in Flanders}

LGBT+ characters and storylines are a mainstay in the fiction television of Flanders, the Dutch-speaking northern part of Belgium. Of the 156 "homemade" fiction productions broadcast on Flemish channels between January 1, 2001, and December

'Ghent University, Belgium

Corresponding Author:

Florian Vanlee, Centre for Cinema and Media Studies, Ghent University, Korte Meer 7,

9000 Ghent, Belgium.

Email: florian.vanlee@ugent.be 
31,2016 , a total of sixty (38.46\%) included LGBT+ roles or narratives, with thirty-six $(23.04 \%)$ of them placing a nonheterosexual or noncisgendered character in a lead role (Vanlee et al., forthcoming-b). Although the significance of this should not be overemphasized, it does point to a significant level of sexual and gender diversity in contemporary Flemish television fiction. In this article, we offer a historical contextualization of the growth of LGBT+ televisibility in Flanders by focusing on the earliest portrayals of sexual and gender diversity in regional domestic fiction series.

With his 2006 monograph Gay TV and Straight America, Ron Becker aptly illustrates how historical contextualization is indispensable in understanding contemporary representational politics informing the portrayal of sexual and gender diversity in popular media. His robust analyses of the conditions and discourses shaping the introduction of gay-themed content in mainstream television resonate with Don Kulick's $(2009,31)$ assertion that these "moments or periods of transition are crucial" in understanding sociocultural constructions of sexuality and gender. Becker's work, alongside that of, for instance, Suzanna Danuta Walters (2003) and Samuel Chambers (2009), has contributed to a deeper understanding of the complex relations between commercial interests, changing societal attitudes toward sexual and gender diversity, and audience expectations.

Although the historical developments associated with LGBT+ televisibility are well known in the context of mainstream popular television in the United States (e.g., Chambers 2009; Hart 2000; Poole 2014; Quimby 2005), knowledge of similar evolutions in other national or even regional contexts is less readily available. Given the intimate relationship between critical queer scholarship and its formative spatial and temporal configurations (Amin 2016; Hall 2002; Muñoz 1999), the frameworks and theoretical tools derived from research like that of Becker (2006) and Walters (2003) cannot simply be transposed to other national television cultures. As such, a wish to understand contemporary popular portrayals of sexual and gender diversity in contexts outside of the United States warrants multifaceted historical analyses as complementary tools to understand both recent and older representations of LGBT + characters and storylines.

In this article, we present a historical contextualization and textual analysis of the three earliest Flemish television fiction series to include LGBT+ characters and storylines, and show how these representations were and remain formative in this numerically significant televisibility of sexual and gender diversity in Flemish television fiction. Every series discussed in this article (Thuis ${ }^{1}$ [TV1, 1995-], Heterdaad ${ }^{2}$ [TV1, 1996-1999], and W8173 [KETNET, 1999-2003]) was produced by Flemish public broadcaster VRT ${ }^{4}$ and aired on affiliated public broadcasting channels. We argue this to be of vital importance, as the VRT's role is meticulously defined and bound by decree in a mission statement directed toward Flemish citizens. This mission statement's translation into representational practices, we show, inverts common understandings of the dynamic between popular culture and normality.

Instead of addressing its audience as an aggregate of consumers, the VRT's mandate preconceives its audience as the collective of Flemish citizens, and formulates the public broadcasting mission as a democratic responsibility (Vlaamse Radio- en 
Televisiemaatschappij [VRT] 1997). We illustrate how this has a particular relationship on the pop-cultural construction of normality, as VRT content is not supposed to cater to the "largest common denominator," as Michael Warner (2000, 69-70) argues concerning commercial mainstream media. Rather, its mandate is formulated in terms that emphasize representing the dynamic nature of Flemish society, and stress the importance of directing attention toward the complexities of contemporaneous social issues (Goossens 1998, 170-71; Van den Bulck 2007, 68, 74).

Our conclusion is that the VRT productions of the late 1990s do contribute to a sexual and gendered normality. Instead of a rigid status quo, the queer normality constructed in VRT content is fundamentally dynamic and open-ended. Queer normality makes visible the inherent contradictions at play in what is socially perceived as normal, acknowledging rather than problematizing these discrepancies. Not subscribing to the binary logic of either heteronormativity or radical queerness, Thuis, Heterdaad, and $W 817$ present LGBT+ storylines as autonomous narratives and refuse to confine them to closed normative and conservative modes of intelligibility. Simultaneously, they avoid communicating an alienating negation of normality altogether. In short, these productions and their LGBT+ narratives represent normality itself as a queer phenomenon.

\section{Television Fiction and Normality/Normativity}

Queer television studies understands individual portrayals and larger representational regimes from a queer theoretical framework that positions the notion of normality as a central benchmark for analysis. Queer theory, Alexander Doty (1993, xv) argues, should "challenge and break apart conventional categories," a foundational claim we often seem to understand as challenging and breaking apart normality (e.g., Chambers 2009; Warner 2000). In his introduction to Fear of a Queer Planet (Warner 1993, xxvi), Michael Warner formulates queer as defining "itself against the normal rather than the heterosexual," emphasizing the moralistic imperative of normality as the chosen target for queer critique. Translated to the applied subfield of queer television studies then, the goal is roughly defined as critiquing the manifold ways in which television tends to normalize LGBT+ identities and identifying those strategies with the potential to subvert sexual and gender normality through popular television (Joyrich 2014).

Normality as a concept is a fundamentally modern phenomenon, closely related to the introduction of statistics as a tool to produce seemingly objective knowledge about societies (Canguilhem 2012). This is not to say that "norms" and "normativity" are purely modern apparitions too: every social formation is characterized by a set of regulations dictating socially sanctioned behavior, with associated outcomes for transgressions (Link and Hall 2004). Norms and normativity are not synonymous to normality, though. With its roots in the statistical description of averages and its transformation into a moralistic sociocultural division between what is "normal" and "abnormal" (Warner 2000), normality is a schizophrenic concept, open to both dynamic and static interpretations with oppositional implications (Stephens 2014). 
The dynamic interpretation of normality is historicized and constructs it as fleeting: a constantly shifting center constituted by its relation to an array of outliers. Normality here is nothing if not purely a product of abnormality. The static interpretation then is dehistoricized: it is the moral privileging of one specific historical normality and its discursive reification into a seemingly natural given (Canguilhem 2012). Here, normality is not an average division on a horizontal axis but the top of a sociocultural hierarchy, a normativity.

The role of mass media such as popular television in sustaining this static conceptualization of normality, in normalization, is well theorized. Although sexual and gender diversity have enjoyed increasing visibility since the 1990s (Becker 2006), the perceived naturalness of cisgendered heterosexuality is often emphasized rather than downplayed through LGBT+ characters and narratives (e.g., Avila-Saavedra 2009; Battles and Hilton-Morrow 2002; Dow 2001; Linneman 2008; Provencher 2005; Westerfelhaus and Lacroix 2006). Consequently, insofar as popular television narratives invite viewer identification and socialization, they tend to encourage straight and LGBT+ viewers alike to assimilate to cisgendered heterosexuality rather than emphasizing the banal normality of abnormality. Becker (2006) especially makes a compelling point in his work on U.S. popular television in the 1990s, illustrating how the consumption of LGBT-flavored programming presented a practical tool to display edgy taste and socially liberal tolerance in the context of the culture wars (Becker 2006, 80-81). This powerfully disarticulates the introduction of sexual and gender diversity to mainstream television from the celebratory progress narratives and instead lays bare the commercial rationale behind this cultural shift.

This is not to say, of course, that static normality is never disavowed through popular television fiction. Premium cable series, such as those under the HBO or Showtime banners, for example, are often cited in queer television studies scholarship as examples of pop-cultural products with a decidedly more subversive and nuanced approach to gender and sexuality (e.g., Chambers 2003, 2009; Dhaenens and Van Bauwel 2012; Munt 2006). Genres such as fantasy and science fiction with a fraught relationship to the mainstream, often with a certain cult sensibility to them, are constructed as another site of queerly antinormative articulations. Series such as Buffy the Vampire Slayer (The WB/UPN, 1997-2003), Torchwood (BBC Three, 2006-2011) and True Blood (HBO, 2008-2014) are much-referenced examples in what could be called the productive side of queer studies, invested in identifying strategies of queer resistance to what is perceived as normality (e.g., Boyer 2011; Burr 2003; Dhaenens 2013; Wilcox 2005).

\section{Contextualizing Normativity}

Queer television studies' stance toward normality thus seems highly dichotomous. Representations of sexual and gender identities can be part of assimilationist discourses urging viewers to conform to heterosexual normality, leading us to disavow them as heteronormative (e.g., Avila-Saavedra 2009; Battles and Hilton-Morrow 2002; Dow 2001; Linneman 2008; Provencher 2005; Westerfelhaus and Lacroix 2006). Alternatively, they present characters and narratives that critique or subvert the ideal 
of cisgendered heterosexuality, leading them to be labeled queer because of their potential to deconstruct normality (e.g., Boyer 2011; Burr 2003; Dhaenens 2013; Wilcox 2005). As such, static normality is not only a productive benchmark in popular television production but to a large extent in queer television studies as well, albeit according to a different logic. Robyn Wiegman and Elizabeth A. Wilson (2015) show that queer scholarship tends to construct normality as static and tyrannical, rather than emphasize its fundamentally fleeting nature both in terms of pop-culture and queer politics. When talking about "normality" then, most work in queer television studies actually refers to "normativity."

Most scholarship on the televisual construction of sexual and gendered normality is derived from U.S. case studies. The television market in the United States is highly liberalized, and the notion of normality is therefore more often than not articulated to issues of the market, as Becker's (2006) and Walters's (2003) work convincingly shows. Audiences addressed as consumers, Warner (2000, 69-70) illustrates, tend to be invited "to aspire to be normal, to adjust their perceptions of themselves and others, so that they fit within the common range." A static interpretation of normality, Warner furthermore shows, arises from commercial media corporations' need to present the world in familiar terms to the largest possible audience to maximize returns on investment. The privileging of one historical normality and the presentation of it as natural and morally superior, then, is closely related to commercial interests and a conservative propensity for safe bets. Conversely, disavowing the same historical normality through television out of commercial interests paradoxically reifies its position as a sociocultural status quo. Antinormality cannot exist without its counterpart, and as such materializes and dehistoricizes what it means to destabilize.

In queer television studies, the politics of normality are often framed in terms of economics and market principles. The question arising here, then, is whether normality and normalization in their dynamic sense have a role to play in queer politics in different national and regional contexts. Specifically, in a television context wherein the mainstream is less of a market than a public domain, and audiences are addressed less as consumers than as citizens, normality might present itself as a potentially queer phenomenon.

\section{Flemish Televised Normality in the I990s}

Given queer television studies' interchangeable use of "normality" and "normativity," it pays to take a look at a distinction made by Jurgen Link and Mirko M. Hall (2004, 18), who understand the first as "postexistent" and the latter as "pre-existent" to action. By this, the authors refer to the fact that normality, as a fundamentally unstable status quo, can only be grasped by observing society rather than dictating it. Normativity, as a static construct, however, presupposes a certain normality that is then used as a regulative principle for society. As the works cited above show, commercial television industry actors tend to opt for the latter option, given their conceptualization of the media landscape as a market. Commercial exploitation, after all, entails a clear standard on how to be a proper consumer as a framework for citizenship. 
Before 1989, the public service broadcasting VRT channel held a monopoly in the Flemish media landscape, and was as such the only provider of what could be called mainstream Flemish television fiction in the domestic media landscape. Although entertainment made up only a modest part of the programming, a number of different genres circulated, ranging from comedy to period drama (Dhoest 2004). The liberalization of the domestic television landscape, influenced by politicians who considered the public broadcaster "too leftist" (Goossens 1998, 116; Saeys 2007, 34), gave way to the introduction of VTM, the first private channel in 1989 (Van Bauwel 2016). Of course, this signaled a profound change in the television landscape. VTM introduced new genres, such as the soap opera (Familie, VTM, 1991), the domestic sitcom (Bompa, VTM, 1989-1994), and the police procedural (Commissaris Roos, VTM, 1990-1992) to the market, attracting mass interest from Flemish audiences (Saeys 2007). The VRT differentiated its television activities in specific channels - general audience channel TV1 (now Één), “quality channel” TV2 (now Canvas), and children's channel KETNET_-in 1997 (Saeys 2007).

Although this change had ramifications on all levels for the public broadcaster, the decree organizing the renewal process was very explicit in two intertwined dimensions: "the commensurability of the PBS with entertainment and maximizing audiences and popular entertainment" (VRT 1997, 1) and the status of the VRT as an institution "attentive to the specific goals on socio-cultural policy of the Flemish communal government" (VRT 1997, 2). Thus, what was essential in the new agreement between VRT and the Flemish communal government in the 1990s was this twofold goal: on one hand, there was an explicit expectation for the VRT to be a constitutive part of the mainstream, while on the other hand, official Flemish policy on social and cultural issues was to be reflected by VRT into the mainstream. This last stipulation does not prescribe interventionism, with government representatives actively shaping the content provided by VRT channels. Rather, it acts as a safeguard to ensure channels funded by Flemish taxpayers reflected and expanded upon the contemporaneous social, cultural, and political debate.

This twofold approach in the 1997 mission statement was considered fundamental to maintain a "quality" public broadcasting service (Saeys 2007). This also implied a prohibition on discriminatory messages, which would be incommensurable with the impartiality expected from the VRT. This policy had clear roots in factual VRT content of earlier decades. In the 1970s, Flemish public television had to be "cutting edge in ethical and sexual debates and play a pioneering role in processes of emancipation," while in the 1980s, it had to touch upon the "important themes of a changing society, such as homosexuality, contraception, breast cancer and divorce" (Van den Bulck 2007, 68, 74). Whereas the VRT, especially during the period of its monopoly in the Flemish television market, could have easily been employed as a profoundly normative institution concerning sexual and gender diversity, it often functioned in just the opposite manner. With its explicit attention to societal changes and ongoing processes of emancipation, the VRT retains an observational attitude toward sociocultural normality, and was institutionally organized to do so. 
In the broader sociocultural context, a similar flexible understanding of normality circulated. Same-sex intimacy has never been illegal in Belgium (Itaborahy and Zhu 2013), and throughout the 1970s and 1980s, LGBT+ movements were quite visible in the public and factored strongly in political debate (Borghs 2016). Advocacy groups were subsidized, and considered important partners in containing the spread of HIV/ AIDS (human immunodeficiency virus infection/acquired immune deficiency syndrome), which furthermore resulted in its explicit dearticulation from homosexuality (Borghs 2016). In this climate, homophobia, and to some extent heterosexism, was increasingly marginalized. The concept of antidiscrimination and acceptance became a mainstay of the Flemish political and cultural mainstream (Van den Bulck and Broos 2011), translated into proclaimed ethical indifference to sexual and gender diversity. In this respect, it is certainly noteworthy that same-sex marriage campaigns focused more on fiscally fair treatment than moral principles, again illustrating the absence of controversy surrounding sexual diversity in itself. Although the infamous Dutroux affair of 1996 did give way to sociocultural anxieties projected on homosexuality overtly disseminated in the mainstream press (Vanlee et al., forthcoming-a), as I discuss below, normality was increasingly revaluated to include sexual and gender diversity, and was framed as such by Flemish media (Borghs 2016).

\section{Just Not That Big of a Deal: Elke in Thuis}

In 1995, generalist VRT channel TV1 formulated a response to the massive popularity enjoyed by the soap opera, Familie (VTM, 1991-) on private channel and sole competitor VTM. With its own soap Thuis (TV1, 1995-), TV1 attempted to imitate VTM's strategy of airing a daily serial immediately after the news broadcast to keep viewers tuned in. Having little experience in long-running fiction shows, the VRT explicitly modeled Thuis on the "community soap model" favored in the United Kingdom, displaying a "natural" cross-section of Flemish society (Dhoest 2007; Franco 2001), while its competitor Familie was and remains a dynastic soap. Christine Geraghty (2005) points out that the community soap opera model is a productive site to address sociocultural issues, because the genre occupies an almost fleeting position between the private and public sphere. In this respect, it is not entirely surprising that the first (female) LGBT+ character surfaced in Thuis's first season: Elke Vervust.

Throughout this first season, Elke evolved from a secondary character to a more fleshed-out role nearing the end of the season. Initially framed as teenage characters Peggy and Bianca's taciturn and dismissive friend, Elke's role grew in importance, as she became a mainstay in the scenes and sequences centered around the younger characters of the soap. These storylines generated an unapologetic perspective on Flemish youth culture in the 1990s, without conservative or moralistic demonization. Peggy, for instance, was shown experimenting with marijuana and XTC with her low-level dealer boyfriend Benny. Whereas Benny's drug dealing was penalized and narratively framed as illicit and unsanctioned behavior, recreational use was not constructed in a paternalistic frame that emphasized risk and danger. Rather, it was presented as simply a part of youth culture, and attention was diverted to the recreational effects of the 
substances. Relationships and sexuality received a similar nuanced treatment: teenage promiscuity was never presented as a social problem, but physically and emotionally abusive behavior was. Thuis thus engaged in representing the everydayness of typical teenage behavior and illustrating the importance of legal and ethical barriers rather than dismissing harmless experimenting as deviant and dangerous from a normative perspective.

Similarly, Elke's sexuality got a detached treatment that emphasized the banalities of her identity rather than reinforcing her status as "non-heterosexual." As a female character clearly not as feminized as the others, yet far from masculinized, Elke's "difference" could easily have been the core of her storylines. Instead, these differences were constantly present yet always downplayed as inconsequential. Her "outing" to male teenage character Steven (Thuis, S01 E69-70), for instance, was not a formalized "confession" of her sexual identity in the heteronormative sense of the term. Taking place in an elliptic narrative void between two separate episodes, the depicted disclosure itself resisted acting as a normative framework (see Chirrey 2003; Dow 2001). Moreover, the narrative weight of the situation was not placed on Elke's desire for women, but on Steven's surprise about her past infatuation with Bianca. The sequence constructs Elke's love as simply desire for a person, and by having her console Steven by stating that she was able to overcome the sadness associated with her unrequited love for Bianca, her queer feelings are brought level with those of heterosexuality, articulating a queer sameness (Dhaenens 2016).

Elke's and Steven's newfound bond over their sensual and/or romantic desire for Bianca provides a narrative backdrop for the audiovisual consolidation of the normality of Elke's identity. Guided by the cinematography of the soap, the audience finds the two in the bar frequented by the teenage characters, peeking at Bianca, inviting viewers to adopt their combined gaze (Thuis, S1 E72-75; see Bordwell 2006). This downplays the gendered nature of the performance of desire acted out by looking at Bianca, and reconstructs it as desire in general, inviting viewers to identify with an attraction they might not share themselves. Elke's desire for her straight friend is not mobilized in a way that frames her love as a problem and narrative stimulant for heterosexual storylines. Rather, it is merely constructed as one of the intertwining narratives in the complexity of the soap opera, rendering it a self-evident component of the dynamic normality portrayed by Thuis.

A similar treatment surfaces at the end of the season. Again, Elke's sexuality is never explicitly brought up in dialogue, and yet her friends all seem up to date, given their lack of astonishment when Elke introduces them to her new girlfriend Jessica (Thuis, S1 E88). Again, this frame downplays the importance of formally coming out as "different" and emphasizes Elke's enthusiasm about having her friends meet the woman she loves instead. A love that is allowed a consummation, moreover, as a passionate and explicit kiss between Elke and Jessica dominated the penultimate scene of the finale on April 6, 1996. Initiated by Elke giving her girlfriend a ring, the kissing scene establishes their desire for each other as sanctioned, respectable, and indeed normal. Elke and Jessica appropriate a significant sociocultural ritual they are institutionally excluded from to show that, regardless of possible future legal recognition, their affection for 
each other is precious to them either way, and they claim agency over how to express it. Furthermore, the fact that Jessica purposefully — and defiantly - flaunts the ring directly to the other characters out of frame substitutes her diegetic audience with the viewer at home. In this sense, she is not bragging to her friends, but normalizing her romantic choice to the Flemish public at large.

\section{Normalizing Queer Faces and Places in Heterdaad}

As a police procedural, the relation of Heterdaad (TV1, 1996-1999) to the idea of Flemish sociocultural normality differs explicitly from that of Thuis. Whereas the latter aims to provide something of a "neutral" cross-section of Flemish society, Heterdaad has a more explicitly binary perspective on "normal" and "abnormal." Given the prominence of crime and felonies, the focus is placed on demarcating the abnormal rather than expanding the normal, as is the case in the community soap opera. This is not to say, however, that normalization is absent in Heterdaad, or that its generic qualities inhibit the construction of a queer version of normality. On the contrary, it is precisely by virtue of genre conventions that Heterdaad is able to address key issues regarding the contingency of sexuality and gender in contemporaneous Flemish society.

The two-episode finale of the second season (February 23 and March 2, 1997) is exceptionally interesting in this regard, because its storyline about a missing child gave way to a homosexual subplot, and because of its conjuncture with the Dutroux affair. ${ }^{5}$ This highly mediatized criminal investigation into Marc Dutroux's abduction and murder of six young girls, led homosexuality to be implicitly articulated with pedophilia in Flemish newspapers (Van den Braembussche 2002; Vanlee et al., forthcoming-a), expanding Heterdaad's fictional storyline to broader discourses that, at first sight, seemed to be perpetuated in the narrative. In the series, a child goes missing after football training in his rural village, and the only plausible suspect happens to be the boy's closeted teacher, Peter Fonteyne, who initially failed to provide an alibi for his whereabouts. The failure to give an alibi, however, is far from the only reason why suspicion falls on Peter. When the officers questioned the boy's parents, they immediately pointed to "that teacher that seemed to be a little too friendly with their son" (S2 E9), whereas the boy's football coach advised the investigators to "have a chat with the fruit" (S2 E9).

Because of the particular context of the Dutroux affair and its ramifications for gay men on the one hand and Peter's status as an initial and innocent (Todorov 1977) suspect on the other, Heterdaad inadvertently occupied a peculiar position in the complexities of gay visibility at the time. As viewers were both acquainted with genre conventions and embedded in the broader sociocultural context of the Dutroux affair, the narrative was imbued with normalizing potential, disavowing prejudice and detaching one's sexual identity from social undesirability. By presenting this particular narrative in its particular context, the message of the episode became more centered on bias and stigmatization than suspense and the thrill of the investigation. Adding further weight to this subversion of pervasive sociocultural discourses on homosexuality is the contrastive depiction of Peter and the other inhabitants of the village. 
Throughout both episodes, Peter is seen caring for his live-in mother, having a heartfelt talk with his ex-boyfriend to confirm his alibi, and at the end, getting back to teaching. In short, Peter has a banal everyday existence temporarily interrupted by the claims made against him. The other inhabitants, however, are shown in a less sympathetic light, not only portrayed as bigoted but also conniving and disingenuous. The football coach is an alcoholic shown committing vandalism, and the missing boy's father (later exposed as the perpetrator) exploited antigay sentiments in the village to deflect suspicion from himself as a tyrannical and violent father, while the boy's uncle attempts to make a pass at his brother's wife while she is grieving her son's death. By virtue of this framing, sexual identity becomes an inconsequential aspect in what is considered normal and abnormal. Through the combined focus on stigmatization and the less than flattering portrayal of those characters intuitively seen as "regular people," Heterdaad discredits sexual and gender identity as a formative criterium of normality, and relegates the "criteria of the normal" to what is best described as common decency instead of the rather arbitrary object of one's desire.

A similar reversal takes place with Willy Martens, one of the show's regulars and a closeted gay man. To check Peter's alibi, Willy and his partner Reggie have to find an unknown patron of a bar in Fontaynas, then a well-known cruising area in Brussels. Visiting Fontaynas, where he might run into friends, does not sit well with Willy, whose inhibition is not exactly diminished by Reggie's rather liberal use of homophobic slurs. The area's atmosphere is seedy and anonymous men in raincoats pass by every now and then, framing the location as illicit, impersonal, and deviant. When Willy is recognized by a friend and invited inside, his outing has de facto taken place, with Reggie uneasily following him inside. His preconception of a gay bar is never verbally expressed, but is abundantly clear from his panicked look, evoking a straight nightmare about queer debauchery. His - and undoubtedly, many of the viewers'expectations prove utterly incorrect as Willy guides him into what is essentially just a bar. Reggie sees his partner and friend mingle with the patrons, going from effeminate twenty-somethings to rugged blue-collar types and flamboyant older men, dancing, drinking, and flirting with each other. The bar and its patrons powerfully show how notwithstanding the fact that many of the men frequenting the bar desire men, it is just a bar, and its roles and uses do not differ from any other bar. Rather than constructing this queer place as a site outside of normality, Heterdaad sets it up to do so, but ultimately shows how the normal permeates those places and emphasizes sameness rather than otherness.

\section{Normality Is Abnormal: W8 I 7}

W817 (KETNET, 1999-2003), a sitcom about college students oriented toward children and young adults between the age of ten and sixteen, treats homosexuality as a mere given by never having gay character Steve coming out in the first place. Instead, W817's young viewers learn of his identity through organic, everyday cues rather than a ritualized coming out intended to establish him as "different" from the other characters. When chatting about love and relationships with others, Steve refers to his 
boyfriend; when attractive acquaintances are discussed, Steve joins the girls in rating men instead of women: his romantic and sexual desire for men is treated as just a fact of life without stressing its importance as an identity marker. This is not to say, of course, that his sexual identity is never mobilized for comedic purposes by other characters. When this happens, however, it never stresses the otherness of his sexuality, but contributes to stressing its banality. As the sitcom habitually employs the normal lives of the other characters in humorous situations and dialogue, its inclusion of Steve's sexuality contributes to constructing homosexuality as a natural part of normality. Similarly, W817 presents female character Birgit's rapid succession of flings and boyfriends as something that may lead to hilarious situations, but is ultimately simply the way she wishes to live her life.

Through its focus on the comic aspects of everyday student life, moreover, W817 succeeds in permanently stressing the very relative nature of what can be considered normal sexual and gendered behavior. Steve's drama, Birgit's arrogance, computer geek Akke's semifunctional sociopathy, party animal Britt's careless perspective on earning her degree, and Tom's pompous pose as a bookless novelist all exemplify a complex relation between what is "normal" and "abnormal." W817's generic mechanics have an affording role in this nuanced portrayal of normality, as the status quo restored at the end of each episode (see Battles and Hilton-Morrow 2002) is a rather queer status quo in the first place. Rather than taking a nuclear family or a group of friends as the "normality" to return to after twenty minutes of sitcom shenanigans, W817 opts for a middle route, wherein the group is both at the same time. Lacking the strict hierarchy and stratified roles of the nuclear family sitcom, as well as the sexualized in-group innuendo of the friend sitcom, the social formation portrayed by $W 817$ is best described as a queer family, wherein the bond between characters is forged on grounds of mutual affection and appreciation that does not translate into the rigidity of the traditional family or the sexual tension of the friend group. The status quo restored at the end of each episode then relies more on the reparation of caring bonds and affection than the restoration of authority or the dismissal of a possible liaison.

Although sexual interest is often relegated to characters outside of the core group, this does not mean that sexuality is absent in $W 817$ and that the sitcom painstakingly avoided the issue because of its youthful target audience. Quite the contrary. Of course, actual sex is never portrayed in a sitcom oriented at ten to sixteen year olds, but it is verbally referred to in nearly every episode, especially in regard to Steve and Birgit. Several episodes in the first season show Steve and his boyfriend Tony on dates, kissing and having lighthearted yet suggestive conversations about their sex life and proclaiming their lust for each other. The focus of these scenes and sequences does not reside in affirming Steve and Tony as "good" monogamous homosexuals that assimilate to heterosexual ideals and practices, but on the playful desire that the two men foster for each other. Emphasis does not lie on "responsible" forms of sexuality wherein the use of condoms is underscored as a way to avoid sexually transmitted diseases (STD) or other cues that would mark their intimacy as "different" or "risky." Rather, the sexual component of their relationship is communicated in terms of mutual attraction, playfulness, and joy. 
As the core of W817's narrative and humoristic drive lies the commensurability of regular and irregular behavior and character traits as equally constitutive components of normality; the series succeeds at constructing a very nuanced idea of sexual and gendered normality. Instead of constructing "normal" men and women, W817 points to the natural abnormalities in everyone, rendering it not so much about man and woman or gay or straight, but about human abnormality as the defining principle of normality itself.

\section{Conclusion}

One concern that might be raised in regard to textual analyses is that it may convey a false sense of gravity or prominence on storylines that were actually minor and/or marginal. In the case of the Flemish examples discussed above, it was precisely the fact that these novel characters and storylines were almost hiding in plain sight that creates political potential. Notwithstanding the fact that these articulations of sexual and gender diversity were manifestly present, they were easily overlooked. Not because they went unnoticed, but because they did not explicitly function as LGBT+ representations per se, but rather as a portrayal of a dynamically constructed normality, supposed to include the diversity of the country. Neither in newspaper reporting nor in trade magazines or the minutes of the VRT directorial board were any of the characters and storylines discussed above contested as inappropriate or offensive. Insofar as these portrayals elicited public responses at all, they were validating and supportive. In general, though, they were not even acknowledged as newsworthy changes in the television landscape. As Paul Borghs $(2016,61)$ has noted in his historical overview of the LGBT+ movement in Belgium, "When the media started paying attention to GLBTQ issues, this was mostly done without polarization and undue sensationalizing." The inclusion of sexual diversity in television fiction was not a hotly contested political issue in Flanders, but something that inconspicuously found its way into the mainstream.

Through its nuanced treatment of sexual and gendered diversity, VRT fiction series from the late 1990s fostered a certain ethical indifference toward nonheterosexual or noncisgendered identities via representations that emphasized an unconditional acceptance of "abnormalities" as ultimately normal instead of proposing assimilation in return for tolerance. Historically, the democratic mission of the VRT has prevented the broadcaster from retaining a secessionist logic, wherein one group of citizens is either culturally excluded from another one on heterosexist ideological grounds, or segmented into a commercially interesting demographic. Because of this, normality was not a prefabricated product to be sold in these programs, but a complex social and cultural phenomenon that had to be approached in an observational rather than a regulatory way. Observation arises from distancing, and a certain dynamic of distancing was key in the VRT's efforts to present a queer version of normality. It facilitated the treatment of sexuality as a fundamental identity component on an individual level, and the depiction of sexuality as not necessarily permeating every facet of one's life. 
This observational and democratically representative stance on normality found in television fiction in the late 1990 s provides a perspective to understand contemporary LGBT+ televisibility in Flanders. Although the portrayal of sexual and gender diversity in Flemish television fiction was and is not without its problematic dimensions (the overrepresentation of gay male characters and the lack of ethnic diversity in LGBT+ characters are of concern for example), the construction of normality as a queer phenomenon in the 1990s allows us to understand the complexities of LGBT+ representations in the specifically Flemish television context. The observations in this article definitely do not entail that everyone is or will be represented in fiction television in Flanders, or even that the local industry has already come a long way. Rather, they point to the fact that diversity is considered a part of normality and is not employed for a contrastive affirmation of a static construction of normality. They show a television culture that is sensitive to sociocultural changes, regardless of commercial or reactionary interests as guiding forces in the dissemination of images. Ultimately, this invites us as queer television scholars to be attentive to television production practices characterized by social observation rather than social regulation. We imagine an industry wherein critics and production professionals jointly contribute to an inclusive television culture sensitive to the changing nature of society.

\section{Declaration of Conflicting Interests}

The authors declared no potential conflicts of interest with respect to the research, authorship, and/or publication of this article.

\section{Funding}

The authors received no financial support for the research, authorship, and/or publication of this article.

\section{Notes}

1. Thuis translates as "Home."

2. Heterdaad translates as "Caught in the Act."

3. W817 is pronounced as Wacht Eens Even and translates as "Wait a Second."

4. VRT stands for Vlaamse Radio- en Televisieomroep (Flemish Radio and Television Broadcaster), and has been named as such since 1998. Until 1998, it was called the Belgische Radio- en Televisieomroep Nederlandstalige Uitzendingen (BRTN: Belgian Radio and Television Broadcaster-Dutch Language Broadcasts), but for reasons of clarity, we will consistently employ the acronym VRT in this article.

5. The Dutroux affair is the name commonly given to the crimes committed by child murderer Marc Dutroux, who was definitively apprehended in August 1996. The public outcry around the case was immense, not only because of the atrocity of the crimes but also because of the defective investigation into the disappearances of girls who had fallen into Dutroux's hands by Belgian police forces. Throughout the 1990s, the affair contributed to a general climate of distrust in Belgium as a state and a noted yet implicit articulation between homosexuality and child abuse in the Flemish written press (see Vanlee et al., forthcoming-b). 


\section{References}

Amin, Kadji. 2016. "Haunted by the 1990s: Queer Theory's Affective Histories." Women's Studies Quarterly 44 (3): 173-89.

Avila-Saavedra, Guillermo. 2009. "Nothing Queer about Queer Television: Televized Construction of Gay Masculinities." Media, Culture \& Society 31 (1): 5-21.

Battles, Kathleen, and Wendy Hilton-Morrow. 2002. "Gay Characters in Conventional Spaces: Will and Grace and the Situation Comedy Genre." Critical Studies in Media Communication 19 (1): 87-105.

Becker, Ron. 2006. Gay TV and Straight America. New Brunswick: Rutgers University Press.

Bordwell, David. 2006. The Way Hollywood Tells It: Story and Style in Modern Movies. Oakland: University of California Press.

Borghs, Paul. 2016. "The Gay and Lesbian Movement in Belgium from the 1950s to the Present." QED: A Journal in GLBTQ Worldmaking 3 (3): 29-70.

Boyer, Sabrina. 2011. “'Thou Shalt Not Crave Thy Neighbor': 'True Blood', Abjection, and Otherness." Studies in Popular Culture 33 (2): 21-41.

Burr, Vivien. 2003. "Ambiguity and Sexuality in Buffy the Vampire Slayer: A Sartrean analysis." Sexualities 6 (3-4): 343-60.

Canguilhem, Georges. 2012. On the Normal and the Pathological. Boston: D. Reidel Publishing Company.

Chambers, Samuel A. 2003. "Telepistemology of the Closet; or, the Queer Politics of Six Feet Under." The Journal of American Culture 26 (1): 24-41.

Chambers, Samuel A. 2009. The Queer Politics of Television. London: I.B. Tauris.

Chirrey, Deborah A. 2003. "I Hereby Come Out': What Sort of Speech Act Is Coming Out?" Journal of Sociolinguistics 7 (1): 24-37.

Dhaenens, Frederik. 2013. "Teenage Queerness: Negotiating Heteronormativity in the Representation of Gay Teenagers in Glee." Journal of Youth Studies 16 (3): 304-17.

Dhaenens, Frederik. 2016. "Reading Gay Music Videos: An Inquiry into the Representation of Sexual Diversity in Contemporary Popular Music Videos." Popular Music and Society 39 (5): 532-46.

Dhaenens, Frederik, and Sofie Van Bauwel. 2012. "Queer Resistances in the Adult Animated Sitcom." Television \& New Media 13 (2): 124-38.

Dhoest, Alexander. 2004. De verbeelde gemeenschap: 50 jaar Vlaamse tv-fictie en de constructie van een nationale identiteit [The imagined community: 50 years of Flemish television fiction and the construction of a national identity]. Vol. 8. Leuven: Leuven University Press.

Dhoest, Alexander. 2007. "The National Everyday in Contemporary European Television Fiction: The Flemish Case." Critical Studies in Television 2 (2): 60-76.

Doty, Alexander. 1993. Making Things Perfectly Queer: Interpreting Mass Culture. Minneapolis: University of Minnesota Press.

Dow, Bonnie. 2001. "Ellen, Television, and the Politics of Gay and Lesbian Visibility." Critical Studies in Media Communication 18 (2): 123-40.

Franco, Judith. 2001. "Cultural Identity in the Community Soap: A Comparative Analysis of Thuis (at Home) and EastEnders.” European Journal of Cultural Studies 4 (4): 449-72.

Geraghty, Christine. 2005. "The Study of Soap Opera." In A Companion to Television, edited by Janet Wasko, 308-23. Hoboken: John Wiley \& Sons.

Goossens, Cas. 1998. Radio en televisie in Vlaanderen: een geschiedenis [Radio and television in Flanders: a history]. Leuven: Davidsfonds.

Hall, Donald E. 2002. Queer Theories. London: Palgrave Macmillan. 
Hart, Kylo-Patrick R. 2000. "Representing Gay Men on American Television.” The Journal of Men's Studies 9 (1): 59-79.

Itaborahy, Lucas, and Jingshu Zhu. 2013. State-sponsored Homophobia: A World Survey of Laws: Criminalisation, Protection and Recognition of Same-sex Love. Brussels: ILGA [International Lesbian, Gay, Bisexual, Trans and Intersex Organisation].

Joyrich, Lynne. 2014. "Queer Television Studies: Currents, Flows, and (Main) Streams." Cinema Journal 53 (2): 133-39.

Kulick, Don. 2009. "Can There Be an Anthropology of Homophobia?” In Homophobias: Lust and Loathing across Time and Space, edited by David A. B. Murray, 19-33. Durham: Duke University Press.

Link, Jurgen, and Mirko M. Hall. 2004. "From the 'Power of the Norm' to 'Flexible Normalism': Considerations after Foucault." Cultural Critique 57 (1): 14-32.

Linneman, Thomas J. 2008. "How Do You Solve a Problem Like Will Truman? The Feminization of Gay Masculinities on Will \& Grace." Men and Masculinities 10 (5): 583-603.

Muñoz, José Esteban. 1999. Disidentifications: Queers of Color and the Performance of Politics. Vol. 2. Minneapolis: University of Minnesota Press.

Munt, Sally R. 2006. "A Queer Undertaking: Anxiety and Reparation in the HBO Television Drama Series Six Feet Under.” Feminist Media Studies 6 (3): 263-79.

Poole, Jay. 2014. "Queer Representations of Gay Males and Masculinities in the Media." Sexuality \& Culture 18 (2): 279-90.

Provencher, Denis M. 2005. "Sealed with a Kiss: Heteronormative Narrative Strategies in NBC's Will \& Grace." In The Sitcom Reader: America Viewed and Skewed, edited by Mary M. Dalton and Laura R. Linder, 177-90. Albany: Suny University Press.

Quimby, Karin. 2005. "Will \& Grace: Negotiating (Gay) Marriage on Prime-time Television.” The Journal of Popular Culture 38 (4): 713-31.

Saeys, Frieda. 2007. "Statuut, organisatie en financiering van de openbare televisieomroep in Vlaanderen. [Statute, organisation and financing of the public television broadcaster in Flanders]". In Publieke Televisie in Vlaanderen: Een Geschiedenis [Public television in Flanders: a history], edited by Alexander Dhoest and Hilde Van Den Bulck, 23-51. Ghent: Academia Press.

Stephens, Elizabeth. 2014. "Normal.” Transgender Studies Quarterly 1 (1-2): 141-45.

Todorov, Tzvetan. 1977. "The Typology of Detective Fiction.” In The Poetics of Prose, edited by Tzvetan Todorov, 42-52. Ithaca: Cornell University Press.

Van Bauwel, Sofie. 2016. "Gendered Television Genres, the Same Old Song: A Case Study of Gendered Television Genres in the North of Belgium." In Gender Equality and the Media: A Challenge for Europe, Vol. 11, edited by Karen Ross and Claudia Padovani, 60-71. London: Routledge.

Van den Braembussche, Antoon. 2002. "The Silence of Belgium: Taboo and Trauma in Belgian Memory." Yale French Studies 102:35-52.

Van den Bulck, Hilde. 2007. "Het beleid van publieke televisie: van hoogmis van de moderniteit naar postmodern sterk merk? [The policy of public television: from modernist celebration to a strong postmodern brand?]". In Publieke televisie in Vlaanderen: een geschiedenis [Public television in Flanders: a history], edited by Alexander Dhoest and Hilde Van Den Bulck, 58-83. Ghent: Academia Press.

Van den Bulck, Hilde, and Deborah Broos. 2011. "Can a Charter of Diversity Make the Difference in Ethnic Minority Reporting? A Comparative Content and Production Analysis of Two Flemish Television Newscasts." Communications 36 (2): 195-216. 
Vanlee, Florian, Sofie Van Bauwel, and Frederik Dhaenens. Forthcoming-a. "Same-Sex Love in Times of Dutroux: The Articulation of Homosexuality with Child Abuse in Late 1990's Flemish Print Media." The Catalan Journal of Communication and Cultural Studies.

Vanlee, Florian, Sofie Van Bauwel, and Frederik Dhaenens. Forthcoming-b. "Sexual Diversity on the Small Screen: Mapping LGBT+ Characters in Flemish Television Fiction (20012016)." Working Paper in Film \& Television Studies.

Vlaamse Radio- en Televisiemaatschappij [VRT] [Flemish Radio and Television Corporation]. 1997. Beheersovereenkomst. Brussels: Vlaamse Overheid.

Walters, Suzanna Danuta. 2003. All the Rage: The Story of Gay Visibility in America. Chicago: University of Chicago Press.

Warner, Michael, ed. 1993. Fear of a Queer Planet: Queer Politics and Social Theory. Vol. 6. Minneapolis: University of Minnesota Press.

Warner, Michael. 2000. The Trouble with Normal: Sex, Politics, and the Ethics of Queer Life. Cambridge: Harvard University Press.

Westerfelhaus, Robert, and Celeste Lacroix. 2006. "Seeing 'Straight' through Queer Eye: Exposing the Strategic Rhetoric of Heteronormativity in a Mediated Ritual of Gay Rebellion." Critical Studies in Media Communication 23 (5): 426-44.

Wiegman, Robyn, and Elizabeth A. Wilson. 2015. "Introduction: Antinormativity's Queer Conventions." Differences 26 (1): 1-25.

Wilcox, Rhonda. 2005. Why Buffy Matters: The Art of Buffy the Vampire Slayer. London: I.B. Tauris.

\section{Author Biographies}

Florian Vanlee is a $\mathrm{PhD}$ candidate at the Department of Communication Studies at Ghent University. He is the principal researcher for the FWO-funded research project 'Sexual Diversity on the Small Screen: a qualitative research into the representation of and public debate about LGBT characters in Flemish television fiction'.

Frederik Dhaenens is an assistant professor at the Department of Communication Studies at Ghent University, where he teaches courses that deal with media, (popular) culture and diversity. His research is situated within the field of critical media studies and cultural studies, while focusing on queer theory, LGBT representation, sex and sexuality, and masculinities in relation to popular culture, with a particular interest for television studies, popular music studies and fan studies.

Sofie Van Bauwel is an associate professor at the Department of Communication studies at the Ghent University were she teaches on cultural media studies, gender and media and television studies. She is part of the CIMS and her main field of interest is gender, media and film and television. She is involved in several projects with a focus on the media as signifying articulations in visual popular culture. 